\title{
China’s Long March towards the Adversarial System: Establishment and Development
}

\section{Na Jiang*}

Beijing Normal University, College for Criminal Law Science, Republic of China

\begin{abstract}
In China's current judicial reform and human rights progress, the growth, development and institutionalization of an adversarial approach to criminal justice in China have paved the way for a changing legal culture since 1996. But the use of non-adversarial controls that do not depend on the accused long still underpins the Chinese legal tradition and remains in some aspects of criminal systems. This paper examines the currently effective legislation on China's undergoing reform on criminal law and criminal justice, particularly on non-adversarial controls retained in its road towards the adversarial system, in order to explore into the major obstacles of, and certain potential for, its transition.

Whilst the use of non-adversarial controls that do not depend on the accused long underpinned the Chinese legal tradition and still remains in some aspects of criminal systems, the growth, development and institutionalization of an adversarial approach to criminal justice in China have paved the way for a changing legal culture since 1996. Following the adoption of first revised Criminal Procedure Law of PRC in 1996 (1996 CPL), the theory and practice of this adversarial mode has allowed a broadening of attitudes towards criminal litigation, so as to redress the imbalance between adversarial challenges by the accused and supervision by either the court or procuratorate. In order to strengthen the accused's right to defence and form a solid structure of equilateral triangle among the three parties, the latest amendment to $1996 \mathrm{CPL}$ effective from 2013, has put into practice more adversarial processes with defense's cross-examination on prosecution witnesses rather than inquisitorial approaches by court or procuratorate. This development evidences an institutional shift from such non-adversarial controls that depend on the court or procuratorate, towards the greater inclusion of adversarial elements in criminal procedures to prevent miscarriages of justice, concerning which the retained controls can be demonstrated in law as follows.
\end{abstract}

\section{CPL: Establishment of the Adversarial System}

Compared with the Criminal Procedure Law adopted in 1979, solely using non-adversarial or inquisitorial controls, $1996 \mathrm{CPL}$ appears to be a milestone to China's reform on procedural systems partly because of establishing the adversarial approach to criminal justice. This seems to be a major change on the legal tradition and procedural system of the inquisitorial mode in criminal trial, though retaining non-adversarial elements to be further reformed, in such aspects as an imbalaced structure among the three parties, lacking rights guarantee of the accused without an equal role and so on. Since the shift of an adversarial approach is mainly featured with dependence on the accused and its relation with other parties in trial, the rights to the accused in criminal litigation could be a key focus of comprehensive attention on the use of non-adversarial controls in the present legislation of Chinese criminal procedure.

\section{General}

The 1996CPL has improved procedural rights of the accused, especially those facing the death penalty, on the basis of the relevant provisions in the Criminal Procedure Law of the PRC in 1979. These rights could be divided into three categories in light of their nature and function on the designed structure and expected balance among the three parties in criminal procedures. The first and foremost is a series of rights concerning the defense or legal aid, which is used for the defending party to oppose the accusing one, explicitly including but not limited to the rights to appearance and cross-examination of witnesses at the core of fair trial and criminal justice. The second is the right to request that a judicial body examine, change or withdraw disadvantageous acts, decisions or judgments of another body, such as that to appeal, to present a petition, to demand withdrawals [1], to apply for reconsideration and to file charges against judges [2], procurators and investigators [3]. The third relates to the principles of equality before the law [4], no conviction without a PC's sentence according to law [5], a public, independent and fair trial [6], ne bis idem and nullapoena sine lege [7]. Despite the possibility of being helpful to prevent miscarriages of criminal justice to a certain degree, the improvements seem to be limited in the sense of non-adversarial elements remained and adversarial controls used in form [8], potentially detrimental to the legislative intentions of rights guarantee and procedural balance [9].

\section{Significant shortcomings in all procedures}

The 1996CPL provides for a system of legal aid in the process of criminal cases 9, which was specified by the 1996 Lawyer Law. But this system is limited to the trial of cases only, rather than all of the stages of criminal proceedings, and compulsorily applicable to such several categories as those facing the death penalty, the blind, deaf or mute, minor defendants, without any entrusted lawyer. This is likely to undermine the protection of the interests of criminal suspects or defendants and even lead to unfair trials and misjudged cases.

Moreover, there still remain some limitations to the relevant provisions, which seems to denigrate the practice of the right to a defence and even remove the balance between both parties of the accused and prosecution in several primary aspects. Firstly, there is the intervening time between when the investigation begins and when the

*Corresponding author: Na Jiang, Associate Professor of Beijing Normal University, College for Criminal Law Science, 100875, Republic of China, Tel: + 86 105880 6183; E-mail: na.jiang@bnu.edu.cn

Received June 04, 2014; Accepted August 21, 2014; Published August 27, 2014

Citation: Jiang N (2014) China's Long March towards the Adversarial System: Establishment and Development. Intel Prop Rights 2: 123. doi:10.4172/23754516.1000123

Copyright: (c) 2014 Jiang N. This is an open-access article distributed under the terms of the Creative Commons Attribution License, which permits unrestricted use, distribution, and reproduction in any medium, provided the original author and source are credited. 
lawyer starts. During this time the advisors cannot provide the legal service in preparing the criminal defence. The criminal suspects have to defend themselves at that stage.

Secondly, defence lawyers cannot read judicial documents or technical testimonials until the PP's examination for prosecution, neither can other defenders read these documents without permission of the PP (People's Procuratorate). Accordingly, they appear not to obtain the main evidence materials, but only opinions recommending prosecution and testimonials considered important to defence. Meanwhile, the lawyers can collect the factual material concerning the alleged crimes, as other defenders can with the permission of the PC (People's Court). However, the problem is that there is no explicit provision in the laws or judicial interpretations concerned, to clearly specify what constitutes this material. This appears to prevent them from reading all the materials which might be necessary for them to have a good preparation of defence in trail of the case [10].

The third limitation is on required conditions for the investigation to obtain evidence. With the consent of witnesses and other units or individuals concerned, defence lawyers may obtain information from them, which inevitably means that some witnesses may refuse. This tends to go against the duty to testify of 'those who have information about a case' pursuant to 1996CPL Article 48. Additionally, it is the case with the difficulties for defence lawyers in collecting information from the victim, their relatives, and witnesses provided by the victim. This lies in the fact that both their consent and the permission of the PP or PC are prerequisites. Without specific applicable conditions, the PP or PC seems arbitrarily to permit or refuse the defence lawyers' application for investigation to obtain evidence or inform witnesses about giving testimony in court. These also appear to remove the balance between the accused and the PP.

The fourth limitation is on adverse measures that fail to safeguard defence lawyers' exercising profession. One is the unfavorable procedure that they have to go through prior to meeting criminal suspects at any stages of criminal process. The 1996CPL stipulated that '[I]f a case involves State secrets, before the lawyer meets with the criminal suspect, he shall have to obtain the approval of the investigation organ.' Without definition on the scope of State secrets or relevant regulation on the use of power, this restrictive provision may influence the effect of their meetings so that the lawyer would not efficiently practise law to safeguard the legitimate rights of criminal suspects. Furthermore, the other measure is the criminal risks that practising lawyers may take in defence work. Since 1997CL Article 306 specifies the crime of defender and agent ad litem's destroying evidence, falsifying evidence, or interfering with witnesses, those intending 'to contravene facts, change their testimony or make false testimony' in criminal procedure will be sentenced to fixed-term imprisonment or criminal detention. This appears to lead to more hazards for defence lawyers in the criminal process and become an expedient for other parties' use to retaliate upon the accused party at a disadvantage.

\section{Remained problems in alternative procedures}

In the procedure for second instance, as one of alternative procedures conditionally applicable to all criminal cases, the hearing approach directly influences the quality of second-instance sentences. 1996 CPL Article 187 provides for the public hearing as the primary approach and the written examination and interrogation as the secondary. Specifically, 'the people's court of second instance shall form a collegial panel and open a court session to hear the case of appeal. Where the collegial panel believes that the facts of the crime are clear after consulting case files, interrogating and questioning the parties, defenders and agents ad litem, it may decide not to open a court session. With respect to a case against which a protest is lodged by the people's procuratorate, the people's court of second instance shall open a court session to hear the case. The public hearing appears to favour correcting misjudged cases more than the written examination, whereas the above combination of both approaches tends not to fully ensure the right of the accused to cross-examination or to a public hearing.

The procedure for review of death sentences is a special system, contributing to a fair trial in hearing capital cases, but 1996CPL Articles 199 to 202 do not mention its specific content, approach or term, in explicitly addressing details, and thus leave much room for application of various approaches to the procedure. As Interpretation of the SPC on Some Issues in Enforcement of the 1996CPL stipulates that the HPCs (Higher People's Courts) review death sentences with a suspension of execution by means of reviewing files without a public hearing, both the SPC and HPCs tend to review death sentences in written by law or regulation. While this approach tends to improve efficiency, and saves both time and resources in reviewing death sentences, the defending party is unlikely to participate in the process or argue his or her own opinions. Inevitably in cases where there is no arraignment, there is little or no chance of the defendants exposing other criminal suspects or crimes before the court, or no legal bases for changing original sentences.

Moreover, the procedure of trial supervision, used for correction of all misjudged criminal cases, has limitations on the conditions for its initiation. The PCs that initiate this procedure are likely not to provide a fair and impartial trial for criminal judgments, but to lead to more miscarriages of justice. As a requirement for the initiation, there must be definite errors in the judgments. However, what amounts to such errors is unclear as there are no explicit provisions setting this out, consequently leaving much room for the PCs or PPs to randomly decide whether to initiate the procedure or not. Moreover, the legal process of examination by the PCs or PPs appears to be another obstacle to the defending party's successful start of the retrial procedure by appeals. It tends to be difficult for this party under disadvantaged circumstances to effectively exercise such legal rights and properly start this procedure for correction of wrongful convictions.

\section{Amendment: Development of the Adversarial System}

As a helpful development in the latest Amendment, ineffective until 2013, the right to access legal counsel is further regulated due to resolution of inconsistencies between Articles 33 and 96 in the current law, 1996CPL. In amended Article 33, the relevant provision of current Article 96 has been retained by providing for suspects' access to legal counsel at the earlier stage in the process, i.e., after the initial interrogation or upon imposition of coercive measures, apart from that a defendant has the right to designate a defender at any time. Regrettably, Amendment would not bring the right to legal assistance promptly following arrest or detention or at all stages of criminal proceedings including the preliminary investigations, but still leaves vulnerable detainees subject to the first interrogation without the suspect's lawyer present or benefit of a lawyer's advice. The gap remains to be filled in for protection of the right of criminal suspects to appoint legal counsel or the duty of the detaining authorities to facilitate such appointments, except for those facing the death penalty and life imprisonment.

Despite no clear articulation of the presumption of innocence, Amendment take a positive step to clearly place the burden of proving defendants' guilty on the prosecutor as a principle. Amended Article 48 
Citation: Jiang N (2014) China's Long March towards the Adversarial System: Establishment and Development. Intel Prop Rights 2: 123. doi:10.4172/2375-4516.1000123

Page 3 of 3

provides that "the onus of proof that a defendant is guilty shall be on the public prosecutor in a public prosecution case", but with an exception unspecified and open to a broad interpretation. Also, Amended Article 35 removes the word "proving" from the responsibility of the defender, whereas a new change on such wording maybe limited in its practical impact, without expression of presumed innocence or the right to silence. Furthermore, a new procedure that allowing courts to call investigators to explain the legality of evidence(amended Article 56), to call on prosecutors to provide evidence of the legality of evidence(amended Article 55), and to require a witness statement to be examined and verified in court before it can serve as the basis for deciding a case (amended Article 59), is intended to safeguard the right of a defendant and his or her lawyers to apply to the court for excluding evidence illegally gathered as they allege, in amended Article 56.

Amendment would enhance procedural protections for suspects and defendants in capital cases and clarify the role of lawyers in the final review process conducted by the SPC, with the potential input of all parties. Specifically, amended Article 120 requires that interrogations of all suspects facing a death sentence or life imprisonment should be recorded in full, albeit without a lawyer's attendance in the meantime, as a court of second instance to hold a hearing in all capital case appeals, provided in amended Article 222. Concerning the review procedure for death sentences, amended Article 239 would broaden the SPC power to hold a hearing itself and revise death sentences, in addition to remanding a case for retrial, and amended article 240 require it question the defendant, listen to the arguments of the defense lawyer if requested to by the lawyer. Meanwhile, this process is also under supervision of the SPP that can submit its opinions to the SPC by law.

\section{References}

1. 1996 Criminal Procedure Law Article 28

2. 1996 Criminal Procedure Law Article 30

3. 1996 Criminal Procedure Law Article 14

4. 1996 Criminal Procedure Law Article 6

5. 1996 Criminal Procedure Law Article 12

6. 1996 Criminal Procedure Law Article 5

7. 1997 Criminal Law Article 10

8. 1996 Criminal Law Article 12

9. 1996 Criminal Procedure Law Article 34

10. 1996 Criminal Procedure Law Article 197 